\title{
Design and Development of Collaborative Office Automation System Based on Hierarchical Structure
}

\author{
Chen WANG ${ }^{1}$, Shuangchang FENG ${ }^{2}$, Pengbo LIU $^{3}$, Xiaochang LIU ${ }^{4}$ \\ ${ }^{1}$ Information Center, Shanghai Institute of Special Equipment Inspection and Technical Research, Shanghai, China \\ ${ }^{2}$ Elevator Inspection Department Shanghai Institute of Special Equipment Inspection and Technical Research, Shanghai, China \\ ${ }^{3}$ Elevator Inspection Department Shanghai Institute of Special Equipment Inspection and Technical Research, Shanghai, China \\ ${ }^{4}$ Special Equipment Operator Testing Center Shanghai Institute of Special Equipment Inspection and Technical Research, Shanghai, China
}

\begin{abstract}
In order to improve the work efficiency, this paper introduces a collaborative office automation system, and describes the main functional modules of the collaborative office automation system. It also describes the demand analysis and hierarchical system architecture design of the collaborative office automation system. The system has the characteristics of continuous and stable operation, which improves the work efficiency of the team and saves resources.
\end{abstract}

\section{Introduction}

With the concept of collaborative management gradually rooted in the hearts of the people, in order to establish an efficient and collaborative operation management mode and improve the management ability, more and more enterprises pay attention to the collaborative office automation system based on people and organization [1]. For many enterprises, it is still carried out in the traditional way in the official document circulation, reimbursement approval, office process approval, and remote office process approval. Therefore, the office efficiency is not high, and the office cycle is relatively long.

In order to solve the above problems, it is necessary to build a high-speed, safe, stable, reliable, economic and practical way to operate collaborative office automation system, so that it could fully realize the enterprise's office automation, information resource sharing, and relatively intelligent decision-making. As a result, it could promote the function transformation and information disclosure, improve work efficiency, reduce internal management costs, and enhance management and supervision capabilities [2].

\section{Requirement analysis}

Collaborative office automation system needs to successfully achieve the following goals: to reduce office expenses and reduce office costs; to share various information resources internally and achieve knowledge regulation and management; to strengthen the communication between employees[3]; to enhance the sense of responsibility of personnel; to improve the overall work efficiency; to realize the electronic process approval; to move towards paperless, efficient and fast office direction; to provide various kinds of information resources for leaders with useful data; to help leaders to understand the situation of the enterprise in time; to provide decision support; to provide a variety of work records for future inquiry; to make reasonable use of spare time and realize remote and mobile office.

In terms of ease of use, the interface and function design need to conform to the daily thinking logic and operation habits of employees, and need to be easy to understand, operate and learn. In terms of reliability, collaborative office automation system needs fault tolerance and easy recovery. The database needs to be backed up regularly and the program files needs to be updated in time to avoid fatal damage caused by software bugs. In terms of portability, the system needs to be easy to install and support cross platform. In terms of stability, as the collaborative office automation system will carry the daily work of most employees, the downtime of its server or the system instability caused by software functional defects will greatly affect the daily work. Therefore, the collaborative office automation system needs to have the stability that can withstand the test of time. The longer the average time between failures is, the better. In terms of security, the system needs to have multilevel security protection measures. The hardware part needs to include periodic backup of system data of file server, UPS preventing external power failure, redundant data backup, etc.; and the software part needs to include regular upgrade of system program files, establishment of internal user access control system, database security settings and the application of network security authentication plug-ins.

\section{System module design}

The functional module diagram of collaborative office 
automation system is shown in Figure 1.

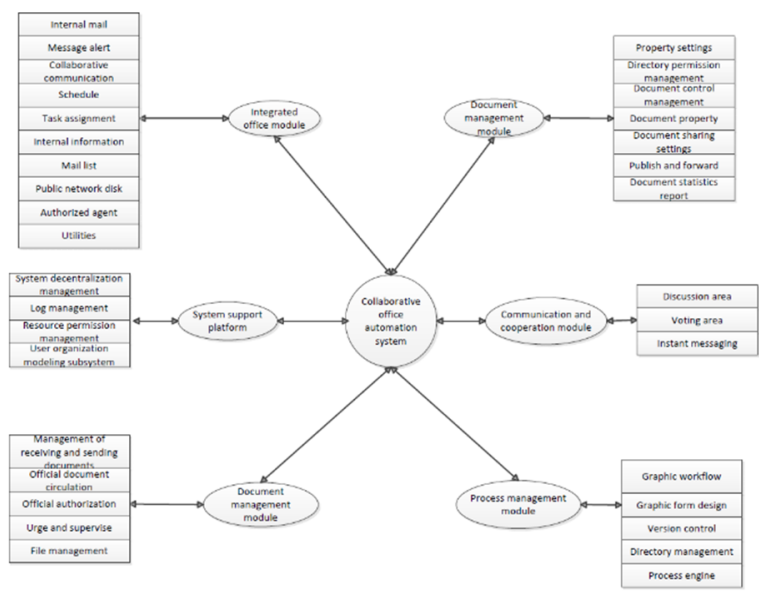

Fig1. Function module diagram of collaborative office automation system

\subsection{Integrated Office Module}

The integrated office module includes internal mail, transaction reminder, collaborative communication, schedule, task assignment, internal information, mail list, public network disk, authorized agent and utilities.

\subsubsection{Internal mail module}

Internal mail module is designed to realize the page integration and reminder of existing e-mail system.

\subsubsection{Transaction reminder module}

Transaction reminder module is designed to remind the amount of transactions involved in OA system, which can be subdivided into "waiting for approval", "task to do", "schedule to do" and other categories. If clicking the link to the specific column, it will view the detailed information and do the corresponding operation.

\subsubsection{SMS reminder module}

SMS reminder module is designed in background, so that it is flexibly set for real-time reminder or timing reminder. This module involves the function of SMS platform.

\subsubsection{Collaborative communication module}

Employees can create new working groups or temporary teams across organizations and regions. Relevant personnel can communicate and report their own work progress [4]. The result file generated by the report is shared within the group. It is convenient for members to know the work progress of cooperative members in time and facilitate the work.

\subsubsection{Schedule module}

The schedule is divided into work schedule and personal schedule. The superior leader with authority checks the work schedule of subordinate employees or arranges work schedule for subordinate employees directly. The personal schedule is not accessible to other people except themselves. Employees arrange a periodic schedule and set the priority of the work schedule. It realizes department level schedule arrangement, and facilitates each department to arrange and share work plans.

\subsubsection{Task assignment module}

Work tasks are assigned to specific personnel. Completion time is set to remind employees when tasks are due, so as to facilitate supervision and urging; the completion of tasks are fed back to the task distributor.

\subsubsection{Internal information module}

Various instant or timing messages are sent and received. The sending mode are set to instant or timing sending.

\subsubsection{Mail list module}

It is divided into personal mail list and public mail list; the public mail list automatically synchronizes the information content of each client's personal account, and no one can modify it except the administrator; the personal mail list provides employees with the information of employees or customers they often contact, and the employees modify and edit themselves; the mail list supports grouping and query by grouping, surname, etc.

\subsubsection{Public network disk module}

The establishment of multi-level directory is supported, which facilitates the sharing of directory. When sharing, reading and modifying permissions are set. The attachment in public file cabinet and internal mailbox are conveniently transferred into personal virtual directory. When sending e-mail, employees directly select files from personal virtual directory. Everyone is able to look up the files shared with him. Space for different directories is allocated by administrators.

\subsubsection{Authorized agent module}

Due to special circumstances, leaders or employees delegate all or part of their authority to different persons for use.

\subsubsection{Utilities module}

Utilities module is designed to release practical information, such as weather forecast $=$, telephone area code, postal code, train time, calendar, world time and other information query, which provides convenience for employees.

\subsection{Communication and Cooperation Module}

Communication and cooperation module includes 
discussion area, voting area, instant messaging and other sub modules.

\subsubsection{Discussion area}

It provides a discussion space for soft management affairs, which is different from daily business processing. Employees establish relevant discussion topics and brainstorm ideas. Different sections are created in the discussion area.

\subsubsection{Voting area}

Employees initiate voting notice of relevant activities or resolutions, and set relevant attributes of voting activities. Employees within the scope of authority vote as required.

\subsubsection{Instant messaging}

The system is embedded with an internal instant messaging tool to facilitate staff communication.

\subsection{Document Management Module}

\subsubsection{Property setting}

This module supports the attribute setting when creating a directory, and automatically classifies the data into the directory according to the attributes.

\subsubsection{Directory permission management}

The authority of the directory (read, write, modify, delete, etc.) is opened to a department or temporarily to an employee; templates are set for documents under the directory to control whether the documents can be downloaded, copied, copied and printed.

\subsubsection{Document control management}

After the expiration date of the document, the list are manually confirmed and completely deleted from the system.

\subsubsection{Document properties}

Document attributes (creation time, creator, modifier, project, customer, etc.) are added according to the requirements, and multi-dimensional query and statistics are supported.

\subsection{Process Management Module}

Workflow is the core content of collaborative office automation system. Workflow is open to users [5]. By creating a process, the applicant determines the sponsor of the process, and then through the process flow, enters the next step of the handler or examiner. The receiver of the next node of the process will receive a reminder in the to- do list of the portal and operate the process by clicking approve or withdraw. At the same time, the operator of the process fills in the processing opinions in the signature comments, and modifies the process to appoint other person to handle [6].

\subsubsection{Workflow requirements}

- It provides graphical workflow customization function, which realizes process nesting, and automatically modifies or adjusts when business changes.

- It provides serial, parallel and distributed processing functions [7], and sets arbitrary complex conditions to determine the flow direction of the process.

- It provides graphical form design function, and the same business form binds multiple different business data tables.

- The process and form are version controlled, imported, exported and backed up.

- Through hierarchical authorization, the relevant personnel manage the process of the division by themselves, and the authority of the process and form are decentralized.

- $\quad$ Form binding, role setting, action setting and permission control are carried out for each step of the process, and corresponding viewing, modifying and controlling permissions are set for different processes [8].

- Form realizes directory management and provides form template library.

\subsubsection{Process management menu}

a) New process: Application templates are divided into the following categories: administrative management, financial reimbursement, procurement, IT management, personnel approval, etc.

b) My request: All kinds of process information applied by employees themselves includes current status, process nodes in progress, etc. According to the process status, employees view the flow records and urge the relevant personnel, and query the application according to various conditions.

c) To do: It lists all the processes that need to be approved by employees themselves. Employees view the application information and circulation records, and query according to the relevant conditions.

d) What has been done: It lists all the processes that have been approved by employees themselves. Employees view the application information and circulation records, and query according to the relevant conditions.

e) Process monitoring: The progress and status of the process are monitored through process log or flow chart, and relevant personnel are urged and supervised if necessary [9].

f) Process setting: The approval template can be set; the graphical workflow customization function can be provided; the workflow can be flexibly designed and 
adjusted; the process node, process trend, process link can be defined, and the corresponding permissions can be set.

g) Process report: The system can provide process custom report and process efficiency analysis report according to requirements.

\section{System architecture design}

\subsection{Overall Architecture Design}

Collaborative office automation system adopts hierarchical structure model, which divides the whole application into display layer, business logic layer and data access layer [10], as shown in Fig 2.

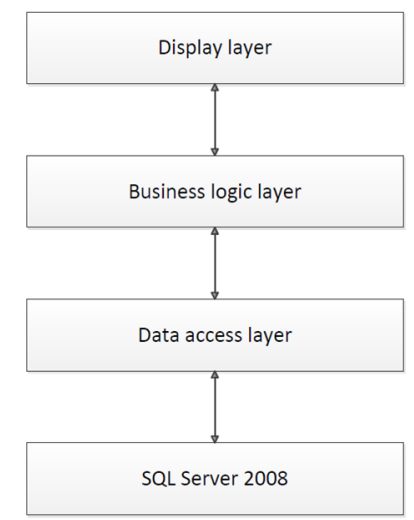

Fig2. System hierarchical architecture design

The display layer is mainly responsible for processing user's input request and output result display, and providing interactive operation for users. The business logic layer is the core layer of the whole system, which is mainly responsible for extracting and saving data from the database and processing the business logic rules of the system. Data access layer is mainly responsible for data query, addition, deletion and modification.

\subsection{Display layer}

Users can access the display layer by inputting the web address of the collaborative office system, enter the account number and password of the system, and enter the main interface of the collaborative office automation system after completing the identity authentication [11]. In the main interface, users can browse the portal, process approval and other operations by accessing the menus at all levels. The display layer provides a standard and unified interface. The data displayed in the interface is read from the background database through the middle business logic layer.

\subsection{Business logic layer}

In the business logic layer, the main business logic and rule implementation of collaborative office automation system is designed by class [12]. These core classes return the result data to the front-end display layer. The establishment of the main business rules and the implementation of the business process are the key points in the business logic layer. The business logic layer plays a key role in the architecture. It is between the data access layer and the presentation layer, and plays a connecting role in data exchange.

\subsection{Data access layer}

The office automation system uses SQL server 2008 as the database. The data access layer is mainly responsible for accessing the background database and updating the data in the database.

\section{Application Benefit Analysis}

\subsection{Improve team efficiency}

The collaborative office system supports remote office and mobile office, and provides a platform for the approval process of mobile phone segment, so that employees can timely handle relevant office affairs when they are on business in other places, make full use of spare time, and improve work efficiency. The comparison of time and efficiency before and after the implementation of the system is shown in Table 1.

Table1. Time efficiency comparison table

\begin{tabular}{|c|c|c|c|}
\hline Workflow Name & $\begin{array}{c}\text { Average } \\
\text { Completion } \\
\text { Time Before } \\
\text { OA } \\
\text { Implementati } \\
\text { on (days) }\end{array}$ & $\begin{array}{c}\text { Average } \\
\text { Completion } \\
\text { Time After OA } \\
\text { Implementation } \\
\text { (days) }\end{array}$ & $\begin{array}{c}\text { Efficiency } \\
\text { Improve } \\
\text { ment }\end{array}$ \\
\hline $\begin{array}{c}\text { Employee leave } \\
\text { application }\end{array}$ & 7 & 2 & $71 \%$ \\
\hline $\begin{array}{c}\text { Equipment } \\
\text { purchase form }\end{array}$ & 7 & 2 & $71 \%$ \\
\hline $\begin{array}{c}\text { Receipt processing } \\
\text { sheet }\end{array}$ & 5 & 1 & $80 \%$ \\
\hline $\begin{array}{c}\text { Contract approval } \\
\text { process }\end{array}$ & 7 & 1 & $85 \%$ \\
\hline $\begin{array}{c}\text { Business trip } \\
\text { application }\end{array}$ & 5 & 2 & $60 \%$ \\
\hline
\end{tabular}

\subsection{Resource saving}

It is difficult to transfer the information in the traditional way. Through paperless way, collaborative automation office system not only improves the efficiency of information flow, but also saves paper resources and human resources

\section{Conclusion}

The planning, research and development of collaborative office system is a comprehensive and complex work. In this paper, the specific requirements of each functional module of the system are proposed combined with the actual situation of the enterprise, and the system is designed and implemented according to the idea of hierarchical architecture, which provides a more convenient and rapid way for information flow, resources saving and economic benefits improvement. 


\section{Acknowledgment}

We gratefully thank the assistance of Shanghai Institute of Special Equipment Inspection and Technical Research for preparing the data and materials.

\section{References}

1. Yang Yang, Jia Jtmdun, and Li Wei-wei /'Application Research of Ofice Automation System Based on J2EE", JISUANJI YU XIANDAIHUA,No.180,pp.185-187, Aug,2010.

2. Gu Ran, "Enterprise office automation system design and implementation[J]", University of electronic science and technology, no. 05, 2013.

3. Wang Zhen, "Office automation[J]", Office automation, no. 22, 2010.

4. He Jiang, "Introduction to the Word of office automation techniques[J]", Journal of taiyuan city vocational and technical college, no. 07, 2012.

5. W. B. Croft and L. S. Lefkowitz, "Using a Planner to Support Office Work", Proceedings of the ACM Conference on Office Information Systems, 1988March.

6. R. E. Fikes and D. A. Henderson, "On Supporting the Use of Procedures in Office Work", Proceedings of the AAAI-80, 1980.

7. Luo Hal-bin, Fan Yu-shun, and Wu Cheng /'Overview of W orkflow Technology", Journal of Software, Vol. 11,No.7,899 907,2000.

8. YAO Xu, "Web Service-Based Workflow Management System", Computer Integrated Manufacturing Systems, V01. 24,No. 1, pp.925-931, Jan. 2006.

9. Yu.L. Leokhin, "The analysis of the information structure of the corporate network", Izvestiyavyshikhuchebnykhzavedeniypovolzhsk iyregiontekhnichtsienauki[University proceedings. Volga region. Technical sciences], no. 4, pp. 27-40, 2008.

10. Saaty T L. The Analytic Hierarchy Process [M]. NewYork:McGraw-Hill. 1980

11. WANG Bin, ZHANG Yunsheng, XIONG Xin, XUE Jie, ZHANG Jing, A semantic based model-driven design method for real-time control software,in Proceedings of the 29th Chinese Control Conference. Washington, DC:IEEE Computer Society, 2010:4257-4262.

12. J. Hox, Multilevel analysis: Techniques and Applications, Lawrence Erlbaum, New Jersey, 2002. 